\title{
THE TOURNAMENT RULES IN FORCE
}

1. The Tournament Director is International Master Mike Valvo. In the event of an appeal against a decision made by the Tournament Director there will be an appeals committee to be nominated by the Board of the ICCA. The decision of the appeals committee will be final in any dispute.

2. The rate of play is 40 moves in 2 hours by each program, and 60 moves in the next hour. After 100 moves the game will be adjudicated by the Tournament Director who may co-opt any other person or use any computer database information he chooses for this purpose. All adjudications will be based on the premise of perfect play by both sides from the adjudicated position.

In exceptional circumstances, e.g., where there have been time outs for communication interrupts totalling more than half an hour, the Tournament Director can decide to adjudicate after 6 hours from the start of the playing session instead of after 100 moves.

3. Unless otherwise advised to the participants, the rounds will start at 16:00 (4:00 p.m.) each day, November $23^{\text {rd }}-27^{\text {th }}$.

4. The tournament will be a 5-round Swiss-System event with "accelerated pairings". This pairing system will bring together stronger programs earlier than would normally be the case with the Swiss System.

The basis for the accelerated pairing system is that the programs will be divided into two halves according to their expected ranking. High-scoring programs in the lower half will not, if possible, be paired against programs from the upper half until the $3^{\mathrm{rd}}, 4^{\text {th }}$ and $5^{\text {th }}$ rounds.

5. The Shannon Trophy and the title of World Computer-Chess Champion will be awarded to the winner of the tournament until the $8^{\text {th }}$ World Computer-Chess Championship takes place (scheduled for North America in 1995). In addition there will be permanent trophies awarded to the top three programs and cash prizes as follows: $1^{\text {st }} \$ 2,500,2^{\text {nd }} \$ 1,000,3^{\text {rd }} \$ 500$.

There are also two additional trophies which have been donated by the magazine Computer-Schach und Spiele, and the ICCA wishes to thank Mr. Ernest Vogel Jun., publisher of the magazine, for his generosity. These trophies will be awarded to the best performance by a Microcomputer and the best performance by an Amateur. An announcement will be made at the start of the tournament to indicate which programs are eligible for each of these special trophies.

In the event of a tie for any of the first three places the prize money will be shared equally. For the purposes of awarding trophies and the World Championship title, ties will be broken as follows:

[i] Sum of opponents' scores.

[ii] Sum of opponents' opponents' scores.

[iii] Successive application of the above until the tie is broken. In the event that it is impossible to break the tie by these means, and if the tie can be reduced to only two programs, a play-off game will be arranged by the Tournament Director. The rate of play for this play-off game will be decided by the Tournament Director after consulting with the operators of both programs. For the tie-break game a coin will be tossed to determine colour. The program operator who wins the toss may choose which colour his program will play. The program which plays Black will win the tie if the game is drawn. "Contempt factors" may be set accordingly.

6. If there is an odd number of participants the program which has the bye each round will score 1 point and this point will be counted in any tie-breaking. 
7. Unless otherwise specified, rules of play are identical to those of regular "human" tournament play. If a point is in question the Tournament Director has the authority to make what he feels is the appropriate decision.

8. A team may request the Tournament Director to stop its clock at most twice during the course of a game because of a technical problem involving the computer system on which the program is executing. The clock must be restarted each time after, at most, 15 minutes. If a team can clearly establish that its problems are not in its own computing system but in the telephone network or in the communications facilities provided in Madrid, the Tournament Director may permit additional time outs.

9. Each game is played on a chess-board provided by our hosts in Madrid. An electronic chess-board used by one side may be substituted if the other side is agreeable. The official chess clock is that provided by our hosts in Madrid.

10. There is no manual adjustment of program parameters during the course of a game. In the case of failures the program parameters must be reset to their original settings if it is at all possible. Information regarding castling status, en passant status, etc., may be typed in after a failure. If at any time during the course of a game the computer asks for the time remaining on either its or its opponent's clock, this information may be provided. The computer must make the request for information. If the computer makes an analogous request such as the connection to a specific database then this request may be carried out.

11. Computer systems whose output is displayed on a monitor should be set up so that the monitor screen is visible to the opposing program operator.

12. Computer operators who wish to interrogate their program to find information such as the program's predicted continuation or assessment, may do so only under the following conditions:

[i] The opposing computer operator must agree, and having agreed has the right at any time to withdraw his agreement.

[ii] The method of interrogating the program must be written down and handed to the opposing operator when the request is made to be allowed to interrogate.

13. At the end of each game, each team is required to present a record of the moves of the game, in algebraic notation, to the Tournament Director.

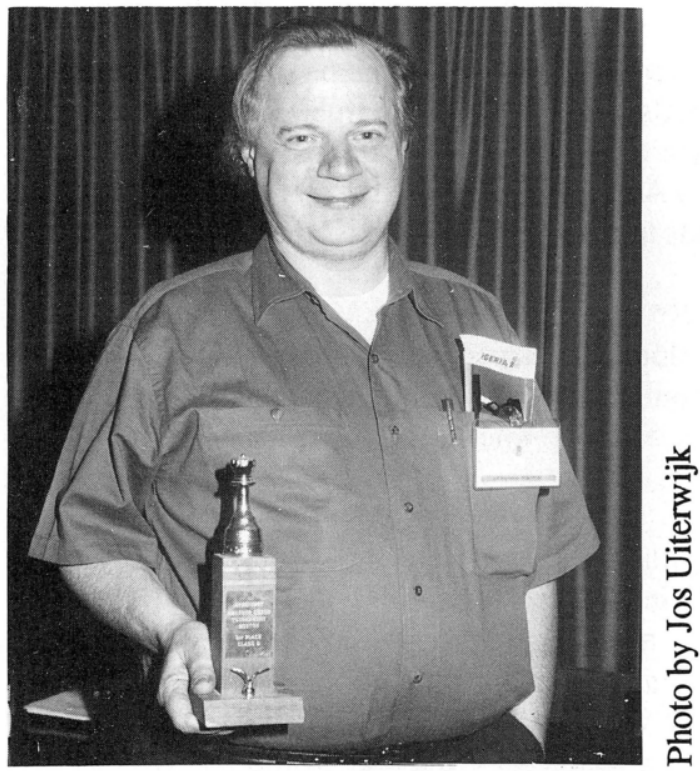

MACHINING A TROPHY OUT OF MEN.

Richard D. Greenblatt showing the first throphy ever to be awarded to a machine playing in a human contest (Madrid, November 27, 1992). 